\title{
O PERFIL DOS VISITANTES DO PARQUE ESTADUAL DO IBITIPOCA (PEIb), LIMA DUARTE, MG ${ }^{1}$
}

\author{
Alecia Silva Ladeira², Guido Assunção Ribeiro ${ }^{3}$, Herly Carlos Teixeira Dias ${ }^{3}$, Carlos Ernesto Gonçalves \\ Reynaud Schaefer ${ }^{4}$, Elpídio Fernandes Filho ${ }^{4}$ e Ary Teixeira Oliveira Filho ${ }^{5}$
}

\begin{abstract}
RESUMO - Este trabalho foi desenvolvido no Parque Estadual do Ibitipoca (PEIb), onde foi realizado um levantamento das características dos visitantes da referida UC, com a finalidade de obter informações sobre o perfil destes. Foram entrevistados 324 visitantes durante os meses de janeiro, fevereiro, abril e junho do ano de 2004, ao passo que os dados de visitação relativos à freqüência mensal e anual de visitantes (19882004) foram fornecidos pela administração da UC. As variáveis utilizadas nas entrevistas foram tabuladas, analisadas e comparadas com a de outras unidades de conservação; dentre elas, observaram-se o nível de escolaridade, a idade, o gênero, o tamanho dos grupos e a origem dos visitantes do PEIb. Como principal resultado, constatouse que a maioria dos visitantes desejava permanecer no parque por mais de dois dias; eles ficaram sabendo da existência do parque por meio da propaganda informal. O perfil dos visitantes mostrou um alto nível de escolaridade, tendo a sua grande maioria segundo grau completo. O principal objetivo da visita foi a busca de um local tranqüilo, de grande beleza cênica proporcionada pelo contato com a natureza. Nos dias atuais, o ecoturismo, além de um modismo, é uma forma de interação e de resgate da vida interiorana, proporcionado pela Vila de Conceição do Ibitipoca, distante apenas $3 \mathrm{~km}$ da portaria do parque.
\end{abstract}

Palavras-chave: Parque Estadual do Ibitipoca, Unidade de Conservação e visitantes.

\section{PROFILE OF VISITORS TO THE IBITIPOCA STATE PARK (PEIb), LIMA DUARTE, MG}

\begin{abstract}
The present work was developed at the State Park of Ibitipoca (PEIb) to assess the characteristics of its visitors to gather information on their profile. A total of 324 visitors were interviewed during the months of January, February, April, and June of 2004, while data related to the frequency of monthly and annual visits (1988-2004) were provided by the administration of the Protected Area. The variables used in the interviews were tabulated, analyzed and compared with other protected areas. The variables education level, age, gender, group size and place of origin of the visitors were obtained. The results mainly showed that visitors staying time in the park was than two days and that they had been informed about through informal advertising. Visitor profile showed a high education level, with most visitors having completed the secondary school level. The main objective of the visit was to search for a quiet place, with great landscape beauty and contact with nature. Nowadays, rather than being just a fad, ecotourism is also a form of interaction and recovery of a traditional life style, provided by the Conceição de Ibitipoca Village, only $3 \mathrm{~km}$ distant from the park entrance.
\end{abstract}

Keywords: Ibitipoca State Park, protected area and visitors.

\footnotetext{
${ }^{1}$ Recebido em 21.02.2006 e aceito para publicação em 28.06.2007.

${ }^{2}$ Engenheira Florestal, D.S. em Ciência Florestal da Universidade Federal de Viçosa. E-mail: <aleciasl@ yahoo.com.br>.

${ }^{3}$ Departamento de Engenharia Florestal da UFV. E-mail: < gribeiro@ ufv.br>.

${ }^{4}$ Departamento de Solos da UFV. E-mail: <carlos.schaefer@ufv.br>.

${ }^{5}$ Departamento de Ciências Florestal da Universidade Federal de Lavras (UFLA). E-mail: <ary@ufla.br>.
} 


\section{INTRODUÇÃO}

Nos dias atuais, em virtude da vida agitada nos centros urbanos e do alto nível de estresse das pessoas, cada vez mais tem aumentado a busca por lugares naturais. O contato com a natureza constitui, atualmente, uma das maiores motivações das viagens de lazer, mas as conseqüências do fluxo em massa de turistas para esses locais devem, necessariamente, ser avaliadas e seus efeitos negativos, evitados, antes que o patrimônio natural se degrade irremediavelmente.

Segundo Brasil (1994), o ecoturismo é discutido desde 1985 no Brasil. No âmbito governamental, a primeira iniciativa de ordenar a atividade ocorreu em 1987, com a criação da Comissão Técnica Nacional, constituída por técnicos do Instituto Brasileiro do Meio Ambiente e dos Recursos Naturais Renováveis - IBAMA e do Instituto Brasileiro de Turismo - EMBRATUR, para monitorar o Projeto de Turismo Ecológico, em resposta às práticas da época, pouco organizadas e sustentáveis. No entanto, nem os esforços governamentais, nem os privados foram suficientes para ultrapassar as barreiras, até hoje existentes, entre a teoria-principalmente em relação aos modelos nacionais - e a prática do ecoturismo.

Considerando a necessidade de atender a essa demanda - visitação em áreas silvestres e a escassez de informações básicas para o adequado manejo dessas áreas -, o maior desafio dos administradores tem sido estabelecer classes de uso, de modo a garantir a conservação da qualidade natural da área e satisfazer as necessidades dos visitantes (TAKAHASHI, 1998).

Segundo Vieira et al. (2000), as áreas de uso público das unidades de conservação foram planejadas para atender a uma demanda menor do que a atual, com atividades menos impactantes e com um público muito diferente daquele que atualmente freqüenta essas áreas naturais protegidas. Para conciliar o uso recreativo dessas áreas com seus objetivos primários, por exemplo a conservação dos recursos naturais e a pesquisa científica, os locais designados para o desenvolvimento de atividades de uso público devem ser manejados para controlar os efeitos negativos sobre o ambiente e garantir a qualidade de experiência do visitante.

De acordo com Roggenbuck e Lucas (1987), conhecer as características básicas dos visitantes, como idade, sexo, escolaridade, permanência no parque e percepção ambiental e ecológica etc., permite compreender melhor quem, quantos, quando, onde e de que modo as pessoas recebem os benefícios das áreas silvestres, sejam eles psicológicos, de comportamento ou sociais. Essas informações podem ajudar os gestores públicos, administradores e pesquisadores a compreender o comportamento dos usuários, bem como as causas e potenciais soluções dos impactos ecológicos e recreativos causados pelos visitantes. Entendendo melhor as características dos visitantes e conhecendo o seu perfil, aumenta-se o profissionalismo de manejo das áreas naturais protegidas, no caso específico o PEIb, e pode-se melhorar a qualidade das suas experiências.

O aumento da visitação em áreas naturais consorciadas com fragilidade de habitats, como é o caso do PEIb, causa impactos ambientais negativos, tanto físicos (compactação do solo, processos erosivos, ruídos), bióticos (afugentamento da fauna, coleta ilegal de material) quanto antrópicos, pois um número elevado de visitantes causa desconforto não somente espacial, como também logístico (dificuldade de estacionamento, filas nos restaurantes). Esses impactos poderiam ser evitados ou diminuídos com algumas propostas de manejo adaptadas para a realidade ambiental da unidade em questão.

O PEIb é caracterizado pela presença de ecossistemas ao mesmo tempo belos, porém extremamente sensíveis ao mínimo impacto ambiental. Localizado em uma das ramificações da serra da Mantiqueira, inserido dentro do bioma Atlântico, o PEIb, basicamente, tem a sua ocupação do solo, caracterizada por Campos Rupestres, Campos de Altitudes e Formações de Vanillosmopis sp., além de um expressivo fragmento de Floresta Estacional Semidecidual Montana (Mata Grande). Hidrograficamente, o ribeirão do Salto e Vermelho, devido à orografia acentuada da localidade, apresentam-se em corredeiras e cachoeiras sobre substrato quartzítico.

Os aspectos bióticos da unidade também são de extrema importância tanto sob a ótica conservacionista quanto científica. Faunisticamente, destacam-se espécies que fascinam tanto pesquisadores quanto visitantes, como Chrysocyon brachiurus (lobo-guará), Puma concolor (onça-parda) e Amazona vinacea (papagaiodo-peito-roxo), dentre outras. A riqueza florística é, ao mesmo tempo, tanto exuberante quanto frágil, onde são encontradas diversas espécies pertencentes às famílias Orquidaceaes, Bromeliaceaes e Melastomeaceaes, dentre outras. 
As grutas em quartzito no PEIb são um atrativo à parte, pois, além de apresentarem uma singularidade espeleológica, são importantes abrigos e refúgios para a fauna silvestre da região, tanto a residente quanto a visitante, como é o caso do andorinhão de coleirafalha (Streptocrone sp.), ave migratória que anualmente visita o PEIb, mas infelizmente vem-se escasseando nos últimos anos. A principal gruta em extensão da unidade é a gruta das Bromélias, com mais de 3.000 $\mathrm{m}$ mapeados, que atualmente se encontra interditada à visitação, devido a riscos de desmoronamentos causados por ações antrópicas.

O clima da Serra do Ibitipoca pode ser classificado como tropical de altitude mesotérmico, com inverno frio e seco e chuvas elevadas no verão. Apresenta temperaturas médias de 12 a $15^{\circ} \mathrm{C}$ na época mais fria e entre 18 e $22^{\circ} \mathrm{C}$ na época mais quente. Além disso, a precipitação pluviométrica está em torno de 200 a $500 \mathrm{~mm}$ ao mês nos períodos chuvosos (principalmente de novembro a março) e, em média, menos de $20 \mathrm{~mm}$ ao mês na época seca (RODELA e TARIFA, 2002).

Pela singularidade ambiental e ecológica, o PEIb é a UC estadual com maior freqüência de visitantes por ano. Em contrapartida é um dos menores parques estaduais em extensão territorial de Minas Gerais, fato esse que, por si só, justifica estudos, levantamentos e diagnósticos voltados para a percepção dos visitantes do PEIb.

Este trabalho teve como objetivo caracterizar o perfil dos visitantes do Parque Estadual do Ibitipoca (PEIb), por meio de questionários elaborados especialmente para a realidade da unidade.

\section{MATERIAL E MÉTODOS}

O Parque Estadual do Ibitipoca (PEIb) foi criado pela Lei 6.126, de 04 de julho de 1973, pertencendo aos Municípios de Lima Duarte, Santa Rita do Ibitipoca e Bias Fortes. Encontra-se entre as coordenadas $21^{\circ}$ 42 'S e $43^{\circ} 54^{\prime} \mathrm{W}$, com área de 1.488 hectares e altitude compreendida entre 1.200 e 1.784 m (pico da Lombada).

Os dados relativos à caracterização do perfil do visitante foram obtidos por meio de questionários (Quadro 1), apresentando perguntas abertas e fechadas, com base nos estudos desenvolvidos por Ruschmann (1991), Takahashi (1998) e Niefer (2002), onde se pretendeu buscar informações qualitativas e quantitativas do perfil do visitante, por meio de um estudo de campo.

Quadro 1 - Modelo do questionário aplicado aos visitantes do PEIb, nos meses de janeiro, fevereiro, abril e junho de 2004 Table 1 - Model of questionnaire applied to PEIb visitors in January, February, April, and June, 2004

1- Ano de nascimento:

Caracterização do perfil do visitante do Parque Estadual do Ibitipoca

2- Sexo: ( ) Masculino ( ) Feminino

3- Grau de escolaridade: ( ) $1^{\mathrm{o}}$ grau incompleto ( ) $1^{\mathrm{o}}$ grau completo ( ) $2^{\mathrm{o}}$ grau incompleto ( ) $2^{\mathrm{o}}$ grau completo ( ) Universitário ( ) Graduado ( ) Pós-graduação ( ) Outros:

Ocupação:

4- Local onde reside:

5- Com que freqüência você visita o Parque? ( ) Primeira vez ( ) até 3 vezes/ano ( ) 4 a 10 vezes/ano

( ) Mais de 10 vezes/ano

6- Quem acompanha você? ( ) Desacompanhado ( ) 2 adultos ( ) 3 a 5 adultos ( ) Família (1 criança)

( ) Família (2 ou + crianças) ( ) Pacote de agências (Excursões) ( ) Grupo com + de 10 pessoas

7- Como soube da existência do Parque? ( ) jornais ( ) televisão ( ) amigos ( ) revista de turismo ( ) família ( ) outros:

8- Qual a importância do Parque para você?

9- Quanto tempo pretende permanecer no Parque? ( ) Até $1 / 2$ dia ( ) O dia todo ( ) 2 dias ( ) Mais de 3 dias

10- Onde você está hospedando durante a visita no Parque? (caso na pergunta anterior a resposta tenha sido mais de uma noite) ( ) Hotel ( ) Pousada ( ) Pensão ( ) Camping do Parque ( ) Camping no Arraial ( ) Casa alugada ( ) morador da Vila ( ) casa de amigos ( ) Outros:

11- Qual sua atividade principal durante a permanência no Parque? ( ) Observar a natureza ( ) Acampar ( ) Nadar/ cachoeira ( ) Caminhar nas trilhas ( ) Outras:

12- Quais os locais/atrativos que você costuma visitar quando vem ao Parque?

13- Você obteve de forma satisfatória as informações para se orientar dentro do Parque (opções, localização e acesso)? ( ) SIM ( ) NÃO ( ) MAIS OU MENOS

14- Você acha que a entrada no Parque deva ser limitada? Sim ( ) Não ( ) Porquê?

15- Você já visitou outro Parque? ( ) SIM ( )NÃO Qual(is)?

16- Qual seu período anual preferido para visitar o Parque? ( ) Primavera (set/out/nov) ( ) Verão (dez/jan/fev)

( ) Outono (mar/abr/mai) ( ) Inverno (jun/jul/ago) ( ) Qualquer época 
De acordo com Takahashi et al. (2005), no Brasil, a limitação de recursos, de equipamentos e principalmente de pessoal, é uma constante. Associado ao desenvolvimento desordenado da recreação em unidades de conservação brasileiras, pode comprometer os objetivos com os quais elas foram criadas. Dessa maneira, foi elaborado um questionário, para uma investigação sistemática do perfil dos visitantes do parque para que, além das características básicas como idade, sexo e escolaridade, pudesse obter informações sobre quais atividades os mesmos desenvolvem durante a sua permanência no parque, época do ano preferida etc.

Foi aplicado um total de 324 questionários em diferentes épocas do ano. As datas de aplicação foram os meses de janeiro, fevereiro, abril e junho de 2004. A escolha desses meses deveu-se ao fato de que, nesses períodos, o PEIb recebe o maior número de visitantes, pois janeiro, além de ser verão, geralmente é um período de férias; fevereiro, carnaval; abril, Semana Santa; e junho, Corpus Christi. A escolha dos visitantes entrevistados foi de forma aleatória, geralmente após terem feito alguma caminhada pelo parque.

Os questionários foram tabulados em um banco de dados do EXCEL e analisados isoladamente, por meio de cruzamentos realizados com o uso da tabela dinâmica, para a obtenção de informações sobre o perfil dos visitantes, recorrendo-se a estatística descritiva, à semelhança de Bonfim et al. (2003), em estudo realizado no entorno do Parque Estadual do Brigadeiro (PESB).
Os dados referentes ao número de visitantes por mês e ano, no período de 1988 a 2004, foram coletados na administração do PEIb (PEREIRA, comunicação pessoal), que controla o fluxo de visitantes através da Portaria da Unidade.

\section{RESULTADOS E DISCUSSÃO}

O PEIb é uma das unidades de conservação do Estado de Minas Gerais, administrada pelo Instituto Estadual de Floresta, MG (IEF), sendo a que recebe o maior número de visitantes anualmente (IEF, 2005). Destaca-se, nesse aspecto, das outras unidades de conservação estadual localizadas em áreas de grande apelo turística, como o Parque Estadual do Itacolomy, em Ouro Preto, e o Parque Estadual do Rola Moça, nas proximidades de Belo Horizonte.

Nos últimos 17 anos (1988-2004), o PEIb recebeu 468.664 visitantes (PEREIRA, comunicação pessoal), gerando uma média de 27.568 visitantes por ano. O número de turistas elevado denota a importância que o PEIb apresenta tanto em termos ambientais, recreacionistas, educativos quanto econômicos, pois a Vila de Conceição de Ibitipoca depende quase que integralmente do parque, onde o turismo alavanca cada vez mais as atividades econômicas do distrito.

O fluxo turístico do PEIb pode ser dividido em dois ciclos de visitação distintos, ou seja, um que vai do período de 1988 a 1994 e o outro de 1995 a 2004 (Figura 1 e 2).

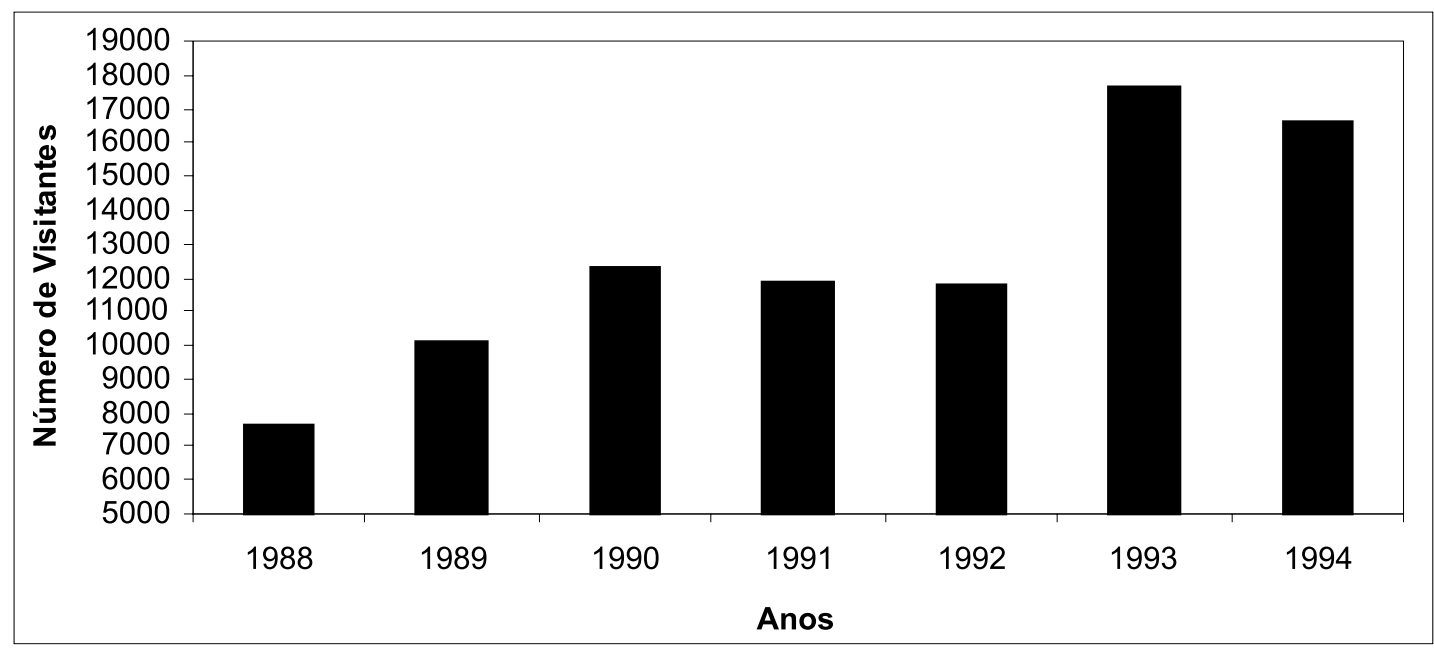

Fonte: J. Pereira, comunicação pessoal. Source: J. Pereira, personal communication.

Figura 1 - Número de visitantes no PEIb, no primeiro ciclo, de 1988 a 1994.

Figure 1 -Number of PEIb visitors during the first cycle, from 1988 to 1994.

R. Árvore, Viçosa-MG, v.31, n.6, p.1091-1098, 2007

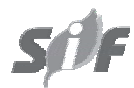




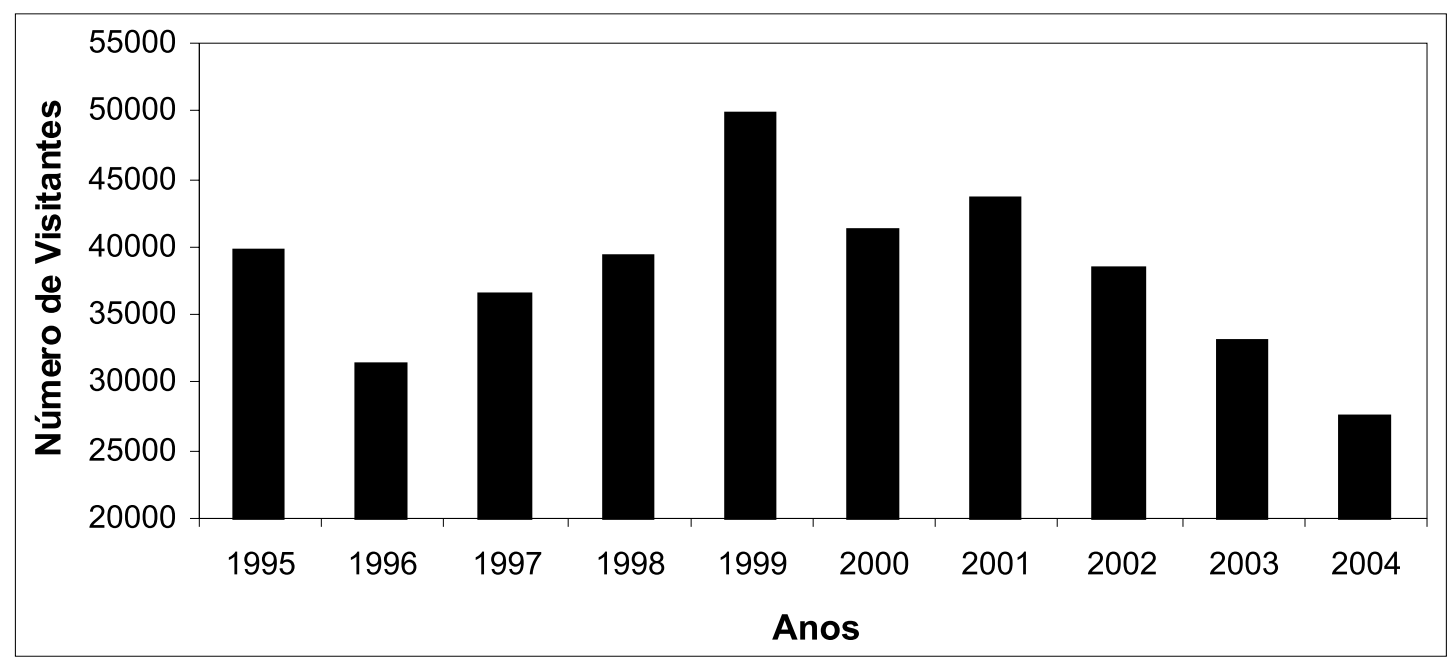

Fonte: J. Pereira, comunicação pessoal. Source: J. Pereira, personal communication.

Figura 2 - Número de visitantes no PEIb, no segundo ciclo, de 1995 a 2004.

Figure 2 -Number of PEIb visitors during the second cycle, from 1995 to 2004.

No primeiro ciclo, que durou sete anos (1988-1994), o parque recebeu um total de 87.931 visitantes, gerando uma média de 12.561/ano. Nesse período, o ecoturismo ainda não era amplamente divulgado e acessível como nos dias de hoje, além do fato de que a consciência ambiental, a percepção e a valoração da natureza eram temas tratados quase que exclusivamente nas salas de aulas das universidades. Durante esse período, de julho de 1993 a dezembro de 1994, o "camping" esteve fechado, e de setembro a outubro de 1994 o parque esteve fechado à visitação, para realização de reformas e obras de infraestrutura, conforme dados documentais na administração do PEIb (PEREIRA, comunicação pessoal).

No segundo ciclo (1995-2004), houve aumento significativo do número de visitantes, quando 380.730 pessoas visitaram o PEIb, resultando uma média de 38.073 visitantes por ano, ou seja, mais de três vezes a média do primeiro ciclo. A partir de 1999, tem-se um decréscimo na visitação, porém há registro, na administração do parque, do porquê dessa variação.

O aumento no número de visitantes pode ser creditado a diversos fatores, dentre os quais, se destacam: o incremento de políticas voltadas para o turismo, com especial ênfase ao ecoturismo, o modismo em visitar unidades de conservação, amparados em valores de conscientização, de preservação e contemplação da natureza e, finalmente, com a popularização e divulgação pela mídia eletrônica. Atualmente, somente em um "site" de busca são encontradas mais de 10.000 páginas contendo a frase "Parque Estadual do Ibitipoca" (GOOGLE BRASIL, 2005).

Em termos de freqüência de visitações mensais, o mês de fevereiro é o que recebe o maior número de turistas, fruto principalmente da estação anual, das férias escolares e do feriado de carnaval, quando o PEIb recebe grande número de turistas oriundos, principalmente, do Município de Juiz de Fora e do Estado do Rio de Janeiro, tendo uma média de visitantes (19882004) de 3.520,82 (Figura 3).

O segundo mês em número médio de visitantes é abril com 3.305,18, em virtude, principalmente, do feriado da Semana Santa, seguido pelo mês de julho, com 3.150,59 visitantes em média, motivado pelo período de férias escolares e pelo inverno relativamente rigoroso, que assim como o verão também atrai visitantes. $O$ mês de janeiro é o quarto na média a receber o maior número de visitantes, com $3.067,23$, por ser também período de férias de verão, apesar das altas taxas de precipitação pluviométrica, o que dificulta a visitação por causa, sobretudo, da dificuldade de acesso. Os meses que apresentam o menor número de visitantes referem-se ao segundo semestre, que vai de agosto a dezembro. Nesses meses, a média de visitantes é de $1.790,63$.

R. Árvore, Viçosa-MG, v.31, n.6, p.1091-1098, 2007 


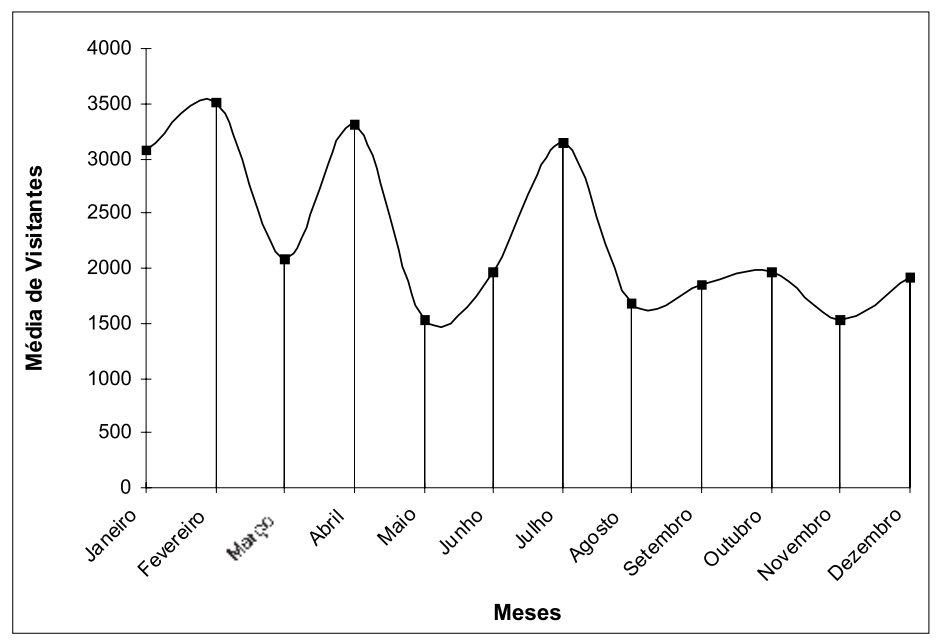

Fonte: J. Pereira, comunicação pessoal. Source: J. Pereira, personal communication.

Figura 3 - Média mensal de visitação do PEIb, Lima Duarte, MG, de 1988 a 2004.

Figure 3 -Average PEIb visits per month, Lima Duarte, MG, from 1988 to 2004.

Outro fator que interferiu na visitação do PEIb e a limitou foi a Portaria IEF $N^{\circ} 36$, de abril de 2003, que estabeleceu normas de visitação e utilização das dependências do Parque Estadual do Ibitipoca, pela qual ficou determinado que o número máximo de visitante é de 300 pessoas ao dia de segunda a sexta e 800 pessoas ao dia nos sábados, domingos e feriados, além das taxas cobradas pela administração para ingresso e estacionamento no parque.

Apesar do significativo número de visitantes que o PEIb recebe anualmente, aliado à fragilidade de seus ecossistemas singulares, o parque ainda não possui o Plano de Manejo Integrado da Unidade, conforme previsto na Lei Federal n ${ }^{\circ}$ 9.985, de julho de 2000.

De acordo com os dados levantados entre os visitantes, observou-se pequena predominância do gênero masculino, com $54 \%$ para os homens e $46 \%$ para as mulheres. De acordo com Moutinho (2000), o número de mulheres que viajam sozinhas ou em grupos aumentou consideravelmente nos últimos anos, sendo isso um fenômeno global devido à sua emancipação social e econômica.

Em relação à idade, de acordo com levantamento a respeito dos visitantes que prestaram informação, foi observado que $41,4 \%$ se encontra na faixa etária de 20 a 29 anos, demonstrando a predominância de público jovem. Porém, é bastante representativa também a faixa de idade de 30 a 39 anos, com $29,6 \%$ dos entrevistados (Figura 4).

R. Árvore, Viçosa-MG, v.31, n.6, p.1091-1098, 2007
Na Figura 5, mostra-se a distribuição do nível de escolaridade dos visitantes que freqüentam o Parque Estadual do Ibitipoca, observando uma predominância de pessoas com nível superior, em que $76 \%$ estão cursando ou possuem o terceiro grau.

Essa característica foi observada por Barros (2003), no Planalto do Parque Nacional do Itatiaia, RJ, onde $33 \%$ dos entrevistados representaram universitários, $20 \%$ os que já completaram algum curso de pós-graduação e $19 \%$ os que possuíam curso superior completo, totalizando $72 \%$ dos visitantes que cursavam ou possuíam o terceiro grau, enquanto $16 \%$ estão cursando ou já completaram o segundo grau.

Em virtude do alto nível de escolaridade dos visitantes entrevistados, pois mais de $92 \%$ possuem o segundo grau completo, espera-se que tal fato favoreça a implantação de projetos de educação ambiental, bem como a adoção das medidas informativas e educativas no sentido de preservar os atrativos e infra-estrutura do parque. Apesar de a situação socioeconômica não determinar a eficácia do processo de acordo com os princípios de educação ambiental, porém esse fato pode contribuir, e muito, para que um programa de educação do visitante seja bem recebido e aceito pelo público, pois as pessoas que visitam o parque já possuem uma bagagem educacional que as ajuda a compreender a importância das atitudes e ações de todos nas áreas naturais. 


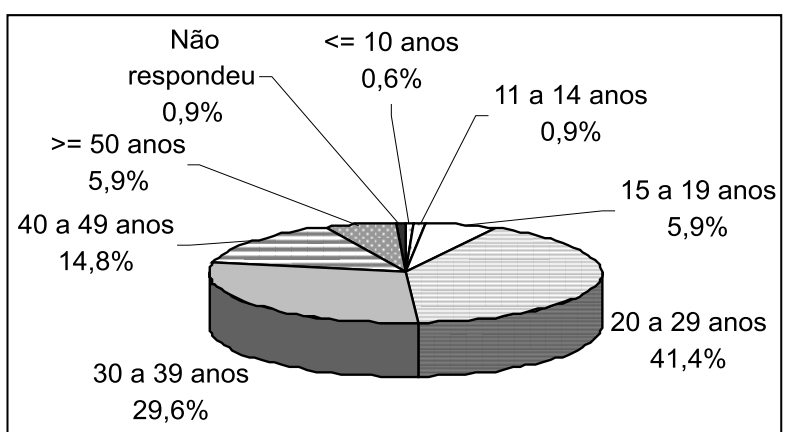

Figura 4-Distribuição da faixa etária dos visitantes entrevistados no PEIb, Lima Duarte, MG nos meses de janeiro, fevereiro, abril e junho, em 2004.

Figure 4-Age group distribution of visitors interviewed at PEIb, Lima Duarte, MG in January, February, April, and June, 2004.

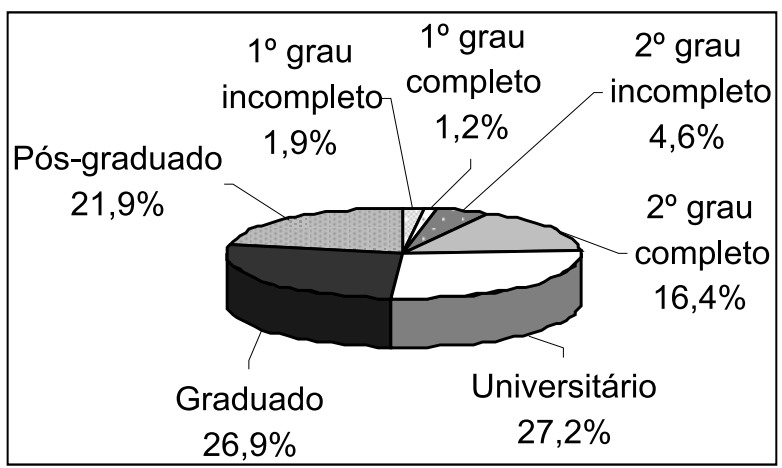

Figura 5 - Distribuição do nível de escolaridade dos visitantes entrevistados no PEIb, Lima Duarte, MG, nos meses de janeiro, fevereiro, abril e junho, em 2004.

Figure 5-Education level distribution of visitors interviewed at PEIb, Lima Duarte, MG, in January, February, April, and June, 2004.

Com relação à formação dos grupos de visitantes constatou-se que $38 \%$ eram compostos de dois adultos, sendo o mesmo número para grupos de três a cinco pessoas, ou seja, aproximadamente $76 \%$ dos grupos que visitavam o PEIb percorriam suas trilhas em grupos de no máximo cinco pessoas.

Ao se relacionar e cruzar os dados através dos questionários utilizando a tabela dinâmica do Excel, foi constatado que, entre os visitantes que foram ao parque pela primeira vez, $90 \%$ possuíam o segundo grau completo, $70 \%$ souberam do parque através de amigos, $49 \%$ estavam hospedados em pousadas, $36 \%$ ficariam no parque por pelo menos dois dias e $33 \%$ tinham a caminhada como sua principal atividade, seguido de $27 \%$ da opção de observar a natureza. Esses dados estão ligados aos visitantes que foram ao parque pela primeira vez.

A grande maioria dos visitantes $(80,6 \%)$ ficou sabendo do parque por meio de amigos e familiares, o que mostra que a propaganda informal é um importante meio de se conhecer a respeito de uma localidade.

Quanto ao estado de origem do visitante, a grande maioria era de Minas Gerais. Dentre esses turistas, 55\% eram originários da cidade de Juiz de Fora, que fica distante do parque apenas $90 \mathrm{~km}$ (Figura 6). Justamente por causa dessa proximidade com o parque, vários visitantes vão apenas passar o dia como forma de descanso, lazer, além do contato com a natureza. Esses tipos de visitantes, que apenas vão passar o dia, não são bem vistos pela população da Vila Conceição de Ibitipoca, pois, via de regra, não agregam valores à economia da Vila, além de contribuírem com a lotação máxima do parque, deixando de fora visitantes que estão hospedados.

Quando questionado sobre o tempo de permanência no parque, $32,4 \%$ dos visitantes entrevistados ficavam mais de três dias, seguido dos $30,3 \%$ que ficavam dois dias, o que mostra que a maioria dos visitantes tinha interesse em conhecer o parque por inteiro, visto que vários atrativos ficam a longa distância e requerem longas caminhadas que duram praticamente o dia todo. Os 30,9\% dos entrevistados responderam ficar apenas por um dia se devem ao fato de o parque estar próximo a diversas cidades e ser um local de descanso, lazer, relaxamento e contato com a natureza.

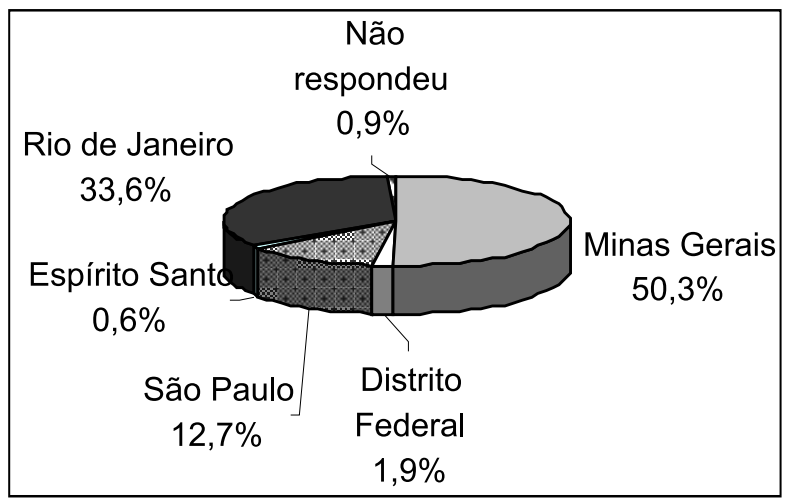

Figura 6 - Estado de origem dos visitantes do PEIb, Lima Duarte, MG, nos meses de janeiro, fevereiro, abril e junho, em 2004.

Figure 6-Place of origin of PEIb visitors, Lima Duarte, MG, in January, February, April, and June, 2004.

R. Árvore, Viçosa-MG, v.31, n.6, p.1091-1098, 2007 
Caminhada e observação à natureza foram citadas por 27,5\% dos entrevistados como a principal atividade praticada durante a visita. Porém, vários entrevistados marcaram duas ou mais opções, sendo $12,4 \%$ dos que responderam que gostavam de caminhar e observar a natureza; sendo esse o mesmo número dos que responderam que gostavam de caminhar, nadare observar a natureza. Apenas $0,9 \%$ respondeu que a principal atividade era acampar.

\section{CONCLUSÕES}

a. Tendo em vista a grande quantidade de atrativos do PEIb, a maioria dos visitantes pretendia conhecer todo o parque, ficando pelo menos dois dias na área.

b. A propaganda informal foi considerada o melhor meio de divulgação do PEIb.

c. Os visitantes do PEIb, no período em que foram entrevistados, apresentaram um alto nível de escolaridade.

d.A maioria dos visitantes do PEIb entrevistados buscava um contato com a natureza e um local de lazer, onde se pode buscar a tranqüilidade.

e. A Vila de Conceição do Ibitipoca é totalmente dependente em termos econômicos do PEIb, através de seus visitantes.

\section{AGRADECIMENTOS}

À FAPEMIG, pela concessão da bolsa de pesquisa, ao IEF, órgão que administra o Parque Estadual do Ibitipoca, onde este trabalho foi realizado; e aos visitantes que se dispuseram a responder ao questionário.

\section{REFERÊNCIAS}

BARROS, M. I. A. Caracterização da visitação, dos visitantes e avaliação dos impactos ecológicos e recreativos do Planalto do Parque Nacional do Itatiaia. 2003. 121f. Dissertação (Mestrado em Recursos Naturais) - Escola Superior de Agricultura Luiz de Queiroz, Piracicaba, 2003.

BONFIM, V. R. et al. Diagnóstico do uso do fogo no entorno do Parque Estadual do Brigadeiro (PESB), MG. Revista Árvore, v.27, n.1, p.87-94, 2003.

BRASIL. Ministério do Meio Ambiente. Diretrizes para uma Política Nacional de Ecoturismo. Brasília: MICT/MMA, EMBRATUR/IBAMA, 1994. 48p.

GoOgle BRASIL. Parque Estadual do

Ibitipoca. Disponível em: <www.google.com.br> Acesso em 23 de agosto de 2005.

R. Árvore, Viçosa-MG, v.31, n.6, p.1091-1098, 2007
INSTITUTO ESTADUAL DE FLORESTAS - IEF. Reformas limitam visitas ao Parque Estadual do Ibitipoca. Disponível em: <http://www.ief.mg.gov.br> Acesso em: 02 de outubro de 2005.

MOUTINHO, L. Segmentation, targeting, positioning and strategic marketing. In: MOUTINHO, L. (Ed.) Strategic management in tourism. New York: CABI Publishing, 2000. p.121-166.

NIEFER, I. A. Análise do perfil dos visitantes das ilhas do Superagüi e do Mel: marketing como instrumento para um turismo sustentável. 2002. 213f. Tese (Doutorado em Engenharia Florestal) - Universidade Federal do Paraná, Curitiba, 2002.

PEREIRA, J. E. Comunicação pessoal. 2004 (Parque Estadual do Ibitipoca, Caixa Postal 16, Lima Duarte-MG, CEP: 36,144-000).

RODELA, L. G.; TARIFA, J. R. O Clima na Serra do Ibitipoca - Sudeste de Minas Gerais. Revista Espaço e Tempo, n.11, 2002.

ROGGENBUCK, J. W.; LUCAS, R. C.

Wilderness use and user characteristics: A state-of-knowledge review. Washington: USDA - Forest Service, 1987 p.201-245. (General Technical Report INT, 220).

RUSCHMANN, D. V. Marketing turístico: um enfoque promocional. Campinas: Papirus, 1991. 128p.

TAKAHASHI, L. Y. Caracterização dos visitantes, suas preferências e percepções e avaliação dos impactos da visitação pública em duas unidades de conservação do estado do Paraná. 1998. 128f. Tese (Doutorado em Ciências Florestais) Universidade Federal do Paraná, Curitiba, 1998.

TAKAHASHI, L. Y.; MILANO, M. S.; TORMENA, C. A. Indicadores de impacto para monitorar o uso público no Parque Estadual do Pico do Marumbi - Paraná. Revista Árvore, v.29, n.1, p.159-167, 2005.

VIEIRA, V.M.M.; PASSOLD, A.J.; MAGRO, T.C. Impactos do uso público: um guia de campo para utilização do método VIM. In: CONGRESSO FLORESTALBRASILEIRO DE UNIDADES DE CONSERVAÇÃO, 2., 2000,Campo Grande. Anais...Campo Grande: Rede Nacional PróUnidades de Conservação, 2000. v.1. p.296-305. 